\title{
Genetic variations in VEGF and VEGFR2 and glioblastoma outcome
}

\author{
S. Sjöström · C. Wibom • U. Andersson · T. Brännström • \\ H. Broholm - C. Johansen - H. Collatz-Laier · Y. Liu • \\ M. Bondy $\cdot$ R. Henriksson $\cdot$ B. Melin
}

Received: 21 July 2010/Accepted: 13 December 2010/Published online: 30 December 2010

(C) The Author(s) 2010. This article is published with open access at Springerlink.com

\begin{abstract}
Vascular endothelial growth factor (VEGF) and its receptors (VEGFR) are central components in the development and progression of glioblastoma. To investigate if genetic variation in VEGF and VEGFR2 is associated with glioblastoma prognosis, we examined blood samples from 154 glioblastoma cases collected in Sweden and Denmark between 2000 and 2004. Seventeen tagging single nucleotide polymorphisms (SNPs) in VEGF and 27 in VEGFR2 were genotyped and analysed, covering $90 \%$ of the genetic variability within the genes. In VEGF, we found no SNPs associated with survival. In VEGFR2, we found two SNPs significantly associated to survival,
\end{abstract}

S. Sjöström · C. Wibom · U. Andersson · R. Henriksson ·

B. Melin $(\triangle)$

Department of Radiation Sciences, Oncology,

Umeå University Hospital, 90187 Umeå, Sweden

e-mail: Beatrice.melin@onkologi.umu.se

T. Brännström

Department of Medical Biosciences, Pathology,

Umeå University, Umeå, Sweden

H. Broholm

Department of Pathology, The Center of Diagnostic

Investigations, Rigshospitalet, Copenhagen University Hospital,

Copenhagen, Denmark

C. Johansen

Institute of Cancer Epidemiology, Danish Cancer Society,

Copenhagen, Denmark

H. Collatz-Laier

Department of ENT Head and Neck Surgery,

Slagelse Hospital, Slagelse, Denmark

Y. Liu $\cdot$ M. Bondy

Department of Epidemiology, MD Anderson Cancer Center,

Houston, TX, USA namely rs2071559 and rs12502008. However, these results are likely to be false positives due to multiple testing and could not be confirmed in a separate dataset. Overall, this study provides little evidence that VEGF and VEGFR2 polymorphisms are important for glioblastoma survival.

Keywords Vascular endothelial growth factor (VEGF) . Vascular endothelial growth factor receptor (VEGFR) . Glioblastoma outcome · Association study · Survival

\section{Introduction}

Gliomas are the most common type of primary brain tumour. The most aggressive of these is glioblastoma, which is associated with very poor prognosis. Apart from age and performance status, few prognostic factors have been identified. Potential prognostic markers found in blood or serum have, however, been proposed, including polymorphisms in low penetrance genes, such as epidermal growth factor (EGF) [1-3], and immune function genes, for instance interleukin 4 (IL4) [4]. Furthermore, hypermethylation of the O6-methylguanine-DNA methyltransferase (MGMT) gene has been found more frequently in longterm survival patients with glioblastoma [5].

Vascular endothelial growth factor (VEGF) is a key factor in both angiogenesis and progression of malignant brain tumours. It has a pro-angiogenic function and increases vascular permeability. Overexpression of VEGF has been found in high grade astrocytoma where its expression also correlates with poor prognosis [6, 7]. Aside from the paracrine effect on endothelial cells, it has recently been shown that VEGF secreted from astrocytoma cells also has an autocrine effect on cell growth and viability. This is mediated via VEGFR2 (KDR), which is co- 
expressed with VEGF by astrocytoma cells, and involves co-activation of the c-Raf/MAPK, P13 K/Akt and PLC/ PKC pathways [6]. The effect is diminished by VEGFR2 inhibition. Furthermore, it has been demonstrated that following radiotherapy there is an inverse correlation between tumour growth rate and expression of both VEGF and VEGFR2 by cancer-related stromal cells, in a subcutaneous mouse model of human colorectal adenocarcinoma. This is consistent with the angiogenic regeneration hypothesis for radiation failure [8]. In the same mouse model, stroma-secreted VEGF was shown to upregulate the VEGFR2 pathway in cancer cells through paracrine interactions, which may also help to explain radiation failure. VEGFR2 inhibition potentiates ionising radiation-induced tumour cell death [6].

We have performed a comprehensive tagging and analysis of germline genetic variants in VEGF and VEGFR2 to elucidate their potential relation to glioblastoma prognosis.

\section{Materials and methods}

\section{Study subjects}

Tumour and blood samples were collected from 176 glioblastoma (ICD-O code 94403) patients diagnosed between September 2000 and March 2004 in Sweden and Denmark, as part of the international Interphone study $[9,10]$. The blood samples were mostly collected within 2 months of diagnosis. A pathology review was performed by two pathologists (T.B. and H.B.). The patients were all between 20 and 69 years of age, and the male/female ratio was 109/ 67. Clinical data regarding (1) date of diagnosis, (2) follow-up date, (3) surgery, (4) radiotherapy and (5) chemotherapy was collected (Table 1). Of these, 50 cases were able to undergo a gross total resection and the remaining cases underwent a subtotal resection or a biopsy. In all, 40 cases received first line therapy containing temozolomide, further information on how the therapy was given and if it was concomitant with radiotherapy was not available. Other chemotherapy regimes given were CCNU (Lomustine), Vincristine and in a few cases NOC (a combination of CCNU, Vincristine and Procarbazin). Different doses of radiotherapy were given, 53 cases received a total dose between 59 and 60 Gray (Gy), 56 cases 50-58 Gy and the remaining cases had total doses from 20 to $44 \mathrm{~Gy}$. The variations of doses were either due to premature termination due to side-effects or progression, or palliative versus curative intention up front. Information on one or more of the treatment parameters was unobtainable in a number of cases, as follows; all treatment data (6 cases), surgery ( 9 cases), radiotherapy (1 case) and chemotherapy (23 cases).
The follow-up time for each patient lasted from date of diagnosis until date of death, alternatively date of last follow-up in the medical journal. Time to last follow-up varied between the different centres. Ten cases were excluded from further analysis due to missing follow-up data and an additional 12 cases were excluded due to missing date of diagnosis; thus, 154 cases remained for the final analyses. A separate dataset was used for confirmation, available from MD Anderson Cancer Center, consisting of 570 glioblastoma cases genotyped with Illumina Infinium HD Human610-Quad BeadChips, as part of a recently performed genome-wide association study [11].

\section{SNP selection}

The single nucleotide polymorphisms (SNPs) selected for genotyping were accessed from the public databases: dbSNP (http://www.ncbi.nih.gov), HapMap (http://www.hapmap. org/) and SNPper (http://snpper.chip.org/). Twenty-seven and 17 specific tagging SNPs were selected for genotyping of VEGFR2 and VEGF, respectively, in order to tag the linkage disequilibrium (LD) and to gain genotype data both from within and surrounding the genes. The SNP selection was performed using the Tagger tool in the Haploview software (http://www.broad.mit.edu/mpg/haploview), with a minimum $r^{2}$ of 0.9. A $5 \%$ minor allele frequency was used in HapMap CEPH (CEU: Utah residents with ancestry from northern and western Europe), to ensure that an LD block inferred information from each SNP in the tag-set.

\section{Genotyping}

DNA extraction was performed by means of conventional methods and quantified using PicoGreen (Invitrogen, Carlsbad, CA, USA). The genotyping was validated on 14 family trios, i.e. 42 individuals, from which genotype data were available through the HapMap consortium. Concordance analyses based on the HapMap data were performed, as well as analyses of the parent-offspring compatibility of the produced genotypes.

As an internal concordance analysis, 90 samples had all included SNPs genotyped in duplicate. Furthermore, to monitor the analytical variability, three separate DNA samples were analysed in quadruplicate on each 364-well plate used. For each SNP genotyping assay, the success rate was calculated as the number of genotypes retrieved divided by the possible number of genotypes.

SNPs genotyping was performed in multiplex format utilising matrix-assisted laser desorption/ionisation timeof-flight mass spectrometry (MALDI-TOF-MS). The SNP assays were designed using the SpectroDESIGNER software (Sequenom, USA). PCR amplification took place in a $5-\mu l$ mixture containing $10 \mathrm{ng}$ genomic DNA, $100 \mathrm{nM}$ of 
Table 1 Distribution of various characteristics of treatment and survival in 176 glioblastoma from Sweden and Denmark

\begin{tabular}{|c|c|c|c|c|c|c|}
\hline & \multicolumn{2}{|c|}{ Sweden $(n=108)$} & \multicolumn{2}{|c|}{ Denmark $(n=68)$} & \multicolumn{2}{|c|}{ Total $(n=176)$} \\
\hline & Total & Missing & Total & Missing & Total & Missing \\
\hline \multicolumn{7}{|l|}{ Survival (months) } \\
\hline Mean & 16.1 & & 15.1 & & 15.7 & \\
\hline Median & 12.4 & & 14.2 & & 12.8 & \\
\hline Range & $2.1-71.8$ & & $1.0-51.9$ & & $1.0-71.8$ & \\
\hline Gross total resection, $n(\%)$ & & $6(5.6 \%)$ & & $1(1.5 \%)$ & $169(96.0 \%)$ & $7(4.0 \%)$ \\
\hline Yes & $26(24.1 \%)$ & & $24(35.3 \%)$ & & $50(29.6 \%)$ & \\
\hline No & $76(70.4 \%)$ & & $43(63.2 \%)$ & & $119(70.4 \%)$ & \\
\hline Chemotherapy, $n(\%)$ & & $13(12.0 \%)$ & & $10(14.7 \%)$ & $153(86.9 \%)$ & $23(13.1 \%)$ \\
\hline Yes & $69(63.9 \%)$ & & $14(20.6 \%)$ & & $83(54.2 \%)$ & \\
\hline Temozolomide & $29(42.0 \%)$ & & $11(78.6 \%)$ & & $40(48.2 \%)$ & \\
\hline No & $26(24.1 \%)$ & & $44(64.7 \%)$ & & $70(45.8 \%)$ & \\
\hline Radiotherapy, $n(\%)$ & & $7(6.5 \%)$ & & $2(2.9 \%)$ & $167(94.9 \%)$ & $9(5.1 \%)$ \\
\hline Yes & $90(83.3 \%)$ & & $57(83.8 \%)$ & & $147(88.0 \%)$ & \\
\hline Total dose 59-60 Gy & $13(14.4 \%)$ & & $40(70.2 \%)$ & & $53(36.1 \%)$ & \\
\hline Total dose $50-58$ Gy & $54(60.0 \%)$ & & $2(12.3 \%)$ & & $56(38.1 \%)$ & \\
\hline Total dose $<50$ Gy & $16(17.8 \%)$ & & $7(12.3 \%)$ & & $23(15.6 \%)$ & \\
\hline Total dose unknown & $7(7.8 \%)$ & & $8(14.0 \%)$ & & $15(10.2 \%)$ & \\
\hline No & $11(10.2 \%)$ & & $9(13.2 \%)$ & & $20(12.0 \%)$ & \\
\hline Number of deaths, $n(\%)$ & $92(85.2 \%)$ & $10(9.3 \%)$ & $66(97.1 \%)$ & & $158(89.8 \%)$ & $10(5.7 \%)$ \\
\hline Sex, $n(\%)$ & & & & & $176(100 \%)$ & \\
\hline Male & $66(61.1 \%)$ & & $43(63.2 \%)$ & & $109(61.9 \%)$ & \\
\hline Female & $42(38.9 \%)$ & & $25(36.8 \%)$ & & $67(38.1 \%)$ & \\
\hline Age median (years) & 56 & & 56 & & 56 & \\
\hline
\end{tabular}

each amplification primer, $500 \mathrm{mM}$ dNTP mix, $1.625 \mathrm{mM}$ $\mathrm{MgCl}_{2}$, and 5.5 units HotStarTaq DNA Polymerase (Qiagen). The mixture was subjected to the following PCR conditions: a single denaturation cycle at $95^{\circ} \mathrm{C}$ for $15 \mathrm{~min}$, followed by 45 cycles at $94^{\circ} \mathrm{C}$ for $20 \mathrm{~s}, 56^{\circ} \mathrm{C}$ for $30 \mathrm{~s}, 72^{\circ} \mathrm{C}$ for $60 \mathrm{~s}$ and a final extension at $72^{\circ} \mathrm{C}$ for $3 \mathrm{~min}$. The Mass EXTEND Reagent Kit was used for the allele-specific extension, in a total of $9 \mu$ with 5 pmol extension primer. The products were cleaned using SpectroCleaner (Sequenom) before being loaded on a 384-element chip nanolinter pipetting system (Sequenom) and subsequently analysed on a MassARRAY mass spectrometer (Bruker Daltonik, Germany). Data analysis was performed using the SpectroTyper software (Sequenom), by two persons independently.

\section{Statistical methods}

Cox-regression modelling was used to estimate survival time as hazard ratios (HR) for carrying different genetic variants of the VEGF or VEGFR genes, with the major allele set as the categorical variable. The analyses were performed using the SPSS software and the HR were adjusted for country, sex, age, surgery (gross total resection or not), radio- and chemotherapy. Rs2071559 was available for confirmation in a data set of 570 glioblastomas collected and analysed at the MD Anderson Cancer Center [11].

\section{Results}

The concordance between the Hap Map data and the data produced on the Hap Map trios was $100 \%$ for all SNPs. No parent-offspring incompatibility was found. The three samples that were analysed repeatedly on each analysis unit consistently showed concordant genotypes for all assays. The success rate for the different SNP assays were all in the range of 96.5-98\%.

We analysed 27 tagging SNPs in VEGFR2 and 17 tagging SNPs in VEGF for association with glioblastoma outcome. In VEGF, we found no significant associations. In VEGFR2, we found one SNP, rs12502008 mapping to intron 1, where homozygosity for the rare allele was associated with longer survival $(\mathrm{HR}=0.45,95 \% \mathrm{CI}$ 0.21-0.95; adjusted for sex, age, country and treatment), 
Table 2 SNPs in the VEGFR2 gene associated with glioblastoma prognosis in cases collected between 2000 and 2004 as part of the Interphone study

\begin{tabular}{|c|c|c|c|c|c|c|c|c|}
\hline rs number & Gene & Region & Major allele & Genotype & No. (\%) & HR $(95 \%$ CI $)$ & $P$ value & Median survival time \\
\hline \multirow[t]{3}{*}{ rs2071559 } & \multirow[t]{3}{*}{ VEGFR2 } & \multirow[t]{3}{*}{ Promotor } & \multirow[t]{3}{*}{$\mathrm{C}$} & $\mathrm{CC}$ & $39(26.0)$ & 1.0 & & 14.0 \\
\hline & & & & $\mathrm{CT}$ & $72(48.0)$ & $1.68(1.06-2.67)$ & 0.028 & 12.1 \\
\hline & & & & TT & $39(26.0)$ & $0.90(0.52-1.56)$ & 0.702 & 13.9 \\
\hline \multirow[t]{3}{*}{ rs 12502008} & \multirow[t]{3}{*}{ VEGFR2 } & \multirow[t]{3}{*}{ Intron 1} & \multirow[t]{3}{*}{ G } & GG & $56(37.1)$ & 1.0 & & 12.5 \\
\hline & & & & GT & $77(51.0)$ & $1.09(0.74-1.62)$ & 0.659 & 12.8 \\
\hline & & & & TT & 18 (11.9) & $0.45(0.21-0.95)$ & 0.036 & 14.7 \\
\hline
\end{tabular}

All hazard ratios $(H R)$ are adjusted for country, sex, age, surgery, radio- and chemotherapy

compared to homozygosity for the common allele. We found no such significant association when we compared heterozygote genotypes with genotypes homozygote for the common allele. In another SNP, rs2071559, located in the promoter region, we saw an association with shorter survival for heterozygote cases compared to homozygote cases for the major allele (HR $=1.68,95 \%$ CI 1.06-2.67; adjusted for sex, age, country and treatment), but here we did not see any significant difference between the homozygote cases for the minor allele and those homozygous for the major allele. All results are shown in Table 2. Rs2071559 was not associated with survival in the MD Anderson Cancer Center dataset (HR $=1.10,95 \%$ CI 0.97-1.24). Rs12502008 was not available in the MD Anderson Cancer Center dataset derived from the Illumina Infinium HD Human610-Quad BeadChips [11].

\section{Discussion}

We have performed a comprehensive tagging of the VEGF and VEGFR2 genes, and an evaluation of their genomic variation's prognostic impact in glioblastoma, and this is, to our knowledge, the first study investigating this correlation. The prognostic impact of VEGF and its receptors has been studied in several different types of cancers, for example breast cancer and colorectal cancer $[12,13]$. We did not have tumour tissue available to correlate VEGF/ VEGFR2 genotypes to other known prognostic factors in glioblastoma [14].

In the VEGF gene, we found no SNPs associated with survival. In the VEGFR2 gene, we found 2 SNPs, one in the promoter region (rs2071559) and one in intron 1 (rs12502008), associated with glioblastoma outcome. We judge our findings as most likely to be false positives. Out of the total of 44 analysed SNPs, we found 2 with a significant association to glioblastoma outcome. This is equivalent to the number of expected false positives, considering that the tests were performed at a 95\% confidence level. Moreover, none of the SNPs we found to be significant displayed a clear dose-response (Table 2), which further supports our assumption. Rs2071559 was confirmed as a false positive through additional testing in an external dataset of 570 glioblastomas, available from the MD Anderson Cancer Center, where it showed no association to survival ( $\mathrm{HR}=1.10,95 \%$ CI 0.97-1.24). Rs12502008 was not available in the MD Anderson Cancer Center dataset. In the VEGF family, three receptors have been identified but earlier studies have shown that activation of VEGFR2 is sufficient to elicit all proangiogenic, proliferation and survival effects associated with VEGF. Although there are three known members of the VEGFR family, activation of VEGFR2 alone is sufficient to bring forth all these effects [8]. Furthermore, inhibition of VEGFR2 has been shown to increase tumour cell death induced by ionising radiation [6]. Taken together, this suggests that VEGFR2 plays a crucial role in glioblastoma development, prognosis, and response to therapy. Genetic variations in this receptor could therefore be of importance for the outcome of these tumours. This hypothesis is, however, not supported by our current study.

Bevacizumab, a monoclonal antibody towards VEGF, has recently been approved for treatment of recurring glioblastoma and is currently the standard second line glioblastoma treatment at many centres. However, none of the patients in this study received Bevacizumab. Hence, we could not evaluate the VEGF and VEGFR2 gene variants' association to response in relation to Bevacizumab treatment. This is nonetheless a highly relevant issue that potentially could have a large impact on treatment decision making [15], and should as such be addressed in future studies including datasets with more homogeneously treated patients that have received anti-angiogenic therapies. In conclusion, our study did not provide support for the hypothesis that polymorphisms in VEGF or VEGFR have an impact on glioblastoma prognosis. 
Acknowledgments The Swedish centre was supported by the Swedish Research Council, the Cancer Foundation of Northern Sweden, the Swedish Cancer Society and the Nordic Cancer Union and the Umea University Hospital Excellence grant. The Danish centre was supported by the Danish Cancer Society. The cases were identified through the Interphone study and supported by the European Union Fifth Framework Program "Quality of life and Management of Living Resources" (contract number QLK4-CT-199901563) and the International Union against Cancer (UICC). The UICC received funds for this purpose from the Mobile Manufacturers' Forum and GSM Association. Provision of funds to the Interphone study investigators via the UICC was governed by agreements that guaranteed Interphone's complete scientific independence. These agreements are publicly available at http://www.iarc.fr/en/researchgroups/RAD/RCAd.html. The views expressed in the publication are those of the authors and not necessarily those of the funders.

Open Access This article is distributed under the terms of the Creative Commons Attribution Noncommercial License which permits any noncommercial use, distribution, and reproduction in any medium, provided the original author(s) and source are credited.

\section{References}

1. Bhowmick DA, Zhuang Z, Wait SD, Weil RJ (2004) A functional polymorphism in the EGF gene is found with increased frequency in glioblastoma multiforme patients and is associated with more aggressive disease. Cancer Res 64:1220-1223

2. Vauleon E, Auger N, Benouaich-Amiel A, Laigle-Donadey F, Kaloshi G, Lejeune J, Delattre JY, Thillet J, Sanson M (2007) The $61 \mathrm{~A} / \mathrm{G}$ EGF polymorphism is functional but is neither a prognostic marker nor a risk factor for glioblastoma. Cancer Genet Cytogenet 172:33-37

3. Sjostrom S, Andersson U, Liu Y, Brannstrom T, Broholm H, Johansen C, Collatz-Laier H, Henriksson R, Bondy M, Melin B: Genetic variations in EGF and EGFR and glioblastoma outcome. Neuro Oncol 12: 815-821

4. Scheurer ME, Amirian E, Cao Y, Gilbert MR, Aldape KD, Kornguth DG, El-Zein R, Bondy ML (2008) Polymorphisms in the interleukin-4 receptor gene are associated with better survival in patients with glioblastoma. Clin Cancer Res 14:6640-6646

5. Krex D, Klink B, Hartmann C, von Deimling A, Pietsch T, Simon M, Sabel M, Steinbach JP, Heese O, Reifenberger G, Weller M, Schackert G (2007) Long-term survival with glioblastoma multiforme. Brain 130:2596-2606

6. Knizetova P, Ehrmann J, Hlobilkova A, Vancova I, Kalita O, Kolar Z, Bartek J (2008) Autocrine regulation of glioblastoma cell cycle progression, viability and radioresistance through the VEGF-VEGFR2 (KDR) interplay. Cell Cycle 7:2553-2561

7. Oehring RD, Miletic M, Valter MM, Pietsch T, Neumann J, Fimmers R, Schlegel U (1999) Vascular endothelial growth factor (VEGF) in astrocytic gliomas-a prognostic factor? J Neuro-oncol 45:117-125

8. Solberg TD, Nearman J, Mullins J, Li S, Baranowska-Kortylewicz J (2008) Correlation between tumor growth delay and expression of cancer and host VEGF, VEGFR2, and osteopontin in response to radiotherapy.Int $\mathrm{J}$ Rad Oncol Biol Phys 72: 918-926

9. Andersson U, Osterman P, Sjostrom S, Johansen C, Henriksson $\mathrm{R}$, Brannstrom T, Broholm H, Christensen HC, Ahlbom A, Auvinen A, Feychting M, Lonn S, Kiuru A, Swerdlow A, Schoemaker M, Roos G, Malmer B (2009) MNS16A minisatellite genotypes in relation to risk of glioma and meningioma and to glioblastoma outcome. Int J Cancer 125:968-972

10. Cardis E, Richardson L, Deltour I, Armstrong B, Feychting M, Johansen C, Kilkenny M, McKinney P, Modan B, Sadetzki S, Schuz J, Swerdlow A, Vrijheid M, Auvinen A, Berg G, Blettner M, Bowman J, Brown J, Chetrit A, Christensen HC, Cook A, Hepworth S, Giles G, Hours M, Iavarone I, Jarus-Hakak A, Klaeboe L, Krewski D, Lagorio S, Lonn S, Mann S, McBride M, Muir K, Nadon L, Parent ME, Pearce N, Salminen T, Schoemaker M, Schlehofer B, Siemiatycki J, Taki M, Takebayashi T, Tynes T, van Tongeren M, Vecchia P, Wiart J, Woodward A, Yamaguchi N (2007) The INTERPHONE study: design, epidemiological methods, and description of the study population. Eur J Epidemiol 22:647-664

11. Shete S, Hosking FJ, Robertson LB, Dobbins SE, Sanson M, Malmer B, Simon M, Marie Y, Boisselier B, Delattre JY, HoangXuan K, El Hallani S, Idbaih A, Zelenika D, Andersson U, Henriksson R, Bergenheim AT, Feychting M, Lonn S, Ahlbom A, Schramm J, Linnebank M, Hemminki K, Kumar R, Hepworth SJ, Price A, Armstrong G, Liu Y, Gu X, Yu R, Lau C, Schoemaker M, Muir K, Swerdlow A, Lathrop M, Bondy M, Houlston RS (2009) Genome-wide association study identifies five susceptibility loci for glioma. Nat Genet 41:899-904

12. Jin Q, Hemminki K, Enquist K, Lenner P, Grzybowska E, Klaes R, Henriksson R, Chen B, Pamula J, Pekala W, Zientek H, Rogozinska-Szczepka J, Utracka-Hutka B, Hallmans G, Forsti A (2005) Vascular endothelial growth factor polymorphisms in relation to breast cancer development and prognosis. Clin Cancer Res 11:3647-3653

13. Kim JG, Chae YS, Sohn SK, Cho YY, Moon JH, Park JY, Jeon SW, Lee IT, Choi GS, Jun SH (2008) Vascular endothelial growth factor gene polymorphisms associated with prognosis for patients with colorectal cancer. Clin Cancer Res 14:62-66

14. Phillips HS, Kharbanda S, Chen R, Forrest WF, Soriano RH, Wu TD, Misra A, Nigro JM, Colman H, Soroceanu L, Williams PM, Modrusan Z, Feuerstein BG, Aldape K (2006) Molecular subclasses of high-grade glioma predict prognosis, delineate a pattern of disease progression, and resemble stages in neurogenesis. Cancer Cell 9:157-173

15. Henriksson R, Bergstrom P, Johansson M, Sandstrom M (2009) Enigma of a rapid introduction of antiangiogenic therapy with bevacizumab in glioblastoma: a new era in the treatment of malignant brain tumours? Acta Oncol 48:6-8 